\title{
On the Role of Embellishment Tones in the Perceptual Segregation of Concurrent Musical Parts
}

\author{
DAVID HURON[1] \\ Ohio State University
}

\begin{abstract}
An analysis of 50 chorale harmonizations by J.S. Bach shows that the use of embellishment tones is consistent with several principles known to contribute to the perceptual segregation of auditory streams. The results imply that a major role of embellishment tones may be to enhance the perceptual independence of the individual parts or voices. In addition, it is shown that Bach tends to distribute embellishment tones in alternating voices. This "turn-taking" is consistent with a single-channel model of attention where asynchronous onset cues are used to refresh the presumed auditory image for each voice.
\end{abstract}

Submitted 2007 March 5; accepted 2007 March 24.

KEYWORDS: voice-leading, auditory streams, figuration tones, non-chordal tones

COMPARED with other musical traditions, one of the hallmarks of Western music has been the widespread use of harmony. The quintessential harmonic practice consists of a succession of block chords such as often occurs in four-part hymnody. But even in the most harmonic of musical textures it is common for composers to introduce tones which either fail to belong to a sounding chord, or deviate from the pattern of synchronized onsets by sounding alone, or both.

These ancillary tones have been designated in different ways by different theorists, including nonharmonic tones (e.g., Piston, 1962), non-chordal tones (e.g., Hindemith, 1944), figuration tones (e.g. Aldwell \& Schachter, 1979) and unessential tones (e.g., Horwood, 1948). The term non-harmonic tone draws attention to the fact that such tones do not change the harmonic function or progression of a passage. The term non-chordal tone recognizes that most such tones do not belong to a given chord. The term figuration tone implies an ornamental or decorative function. The term unessential tone suggests that these tones have a secondary importance and may be discarded without changing the basic character of a musical passage. In this study, we will use the term embellishment tone since, as we will see, some of these tones may be members of a chord or participate in defining a harmonic function; at the same time, the term embellishment has a less derogatory connotation than unessential.

Western music theorists have produced a widely accepted taxonomy for classifying embellishment tones. According to this taxonomy, embellishment tones are categorized according to five criteria:

1. whether or not the tone belongs to a sounding chord

2. whether or not the tone appears in a metrically accented position

3. whether or not the tone is approached by a scale step

4. whether or not the tone is resolved or left by step, and

5. the pitch contour created by the presence of the embellishment (e.g., up-up, up-down, down-up, etc.).

Although variations in nomenclature exist, most types of embellishment tones have widely accepted names; these include passing tones, neighbor tones, appoggiaturas, escape tones, anticipations, pedal tones, changing tones, retardations, and suspensions. In addition to these non-chordal embellishment tones, there are also chordal embellishment tones, such as repetitions, and arpeggiations. Table 1 characterizes each of the various types of embellishment tones according to the five criteria outlined above; a musical illustration of each type of embellishment is provided in Figure 1. 
Table 1

Types of Chordal and Non-Chordal Embellishments

\begin{tabular}{l|lll}
\hline Embellishment & Approach & Resolution & $\begin{array}{l}\text { Metric } \\
\text { Position }\end{array}$ \\
\hline Accented passing tone & Step & Step (in same direction) & Accented \\
Unaccented passing tone & Step & Step (in same direction) & Unaccented \\
Upper neighbor tone & Ascending step & Step (in opposite direction) & Unaccented \\
Lower neighbor tone & Descending step & Step (in opposite direction) & Unaccented \\
Accented upper neighbor & Ascending step & Step (in opposite direction) & Accented \\
Accented lower neighbor & Descending step & Step (in opposite direction) & Accented \\
Anticipation & Step or leap & Same pitch & Unaccented \\
Suspension & Same pitch & Descending step & Accented \\
Retardation & Same pitch & Ascending step & Accented \\
Escape tone & Step & Leap & Unaccented \\
Appoggiatura & Leap & Step & Accented \\
Changing tone & Step & Leap then step & \\
Pedal tone & Same pitch & Same pitch & Unaccented \\
Repetition tone* & Same pitch & Any movement & Unaccented \\
Arpeggio tone* & Leap & Any movement & \\
\hline
\end{tabular}

*Chordal embellishments
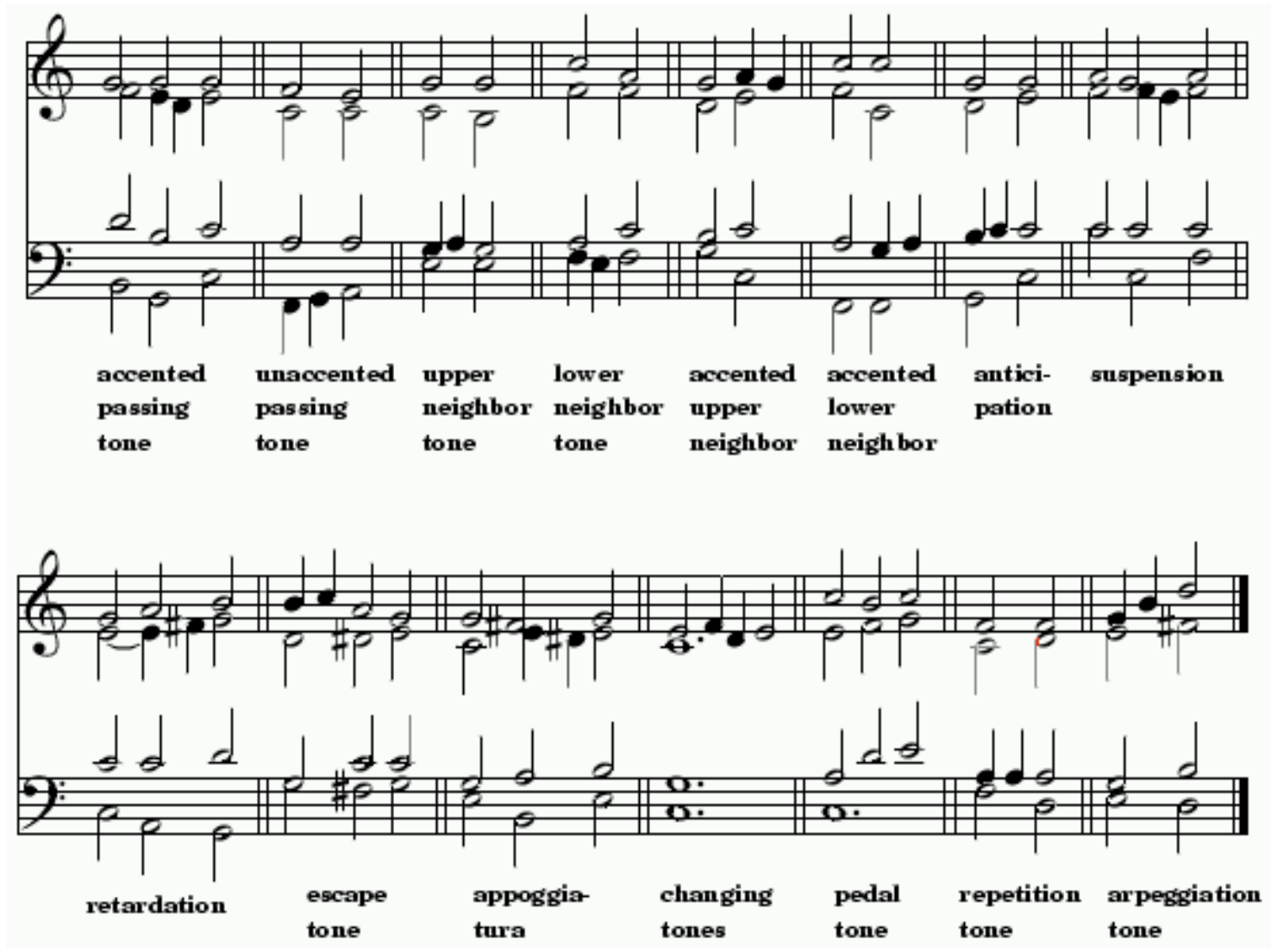

Fig. 1. Musical illustrations of fifteen embellishment tones, including accented and unaccented passing tones, accented and unaccented upper and lower neighbor tones, the anticipation, suspension, retardation, escape tone, appoggiatura, changing tones and the pedal tone. In addition to non-chordal embellishment tones, two chordal embellishment tones are illustrated: the repetition and arpeggiation. Refer to Table 1 for taxonomic criteria. 


\section{THEORETICAL ACCOUNTS OF EMBELLISHMENT TONES}

A number of accounts have been proposed regarding the origin and musical function of embellishment tones. A common theme in many accounts is that embellishment tones add interest to a musical texture. Such interest might arise, for example, by adding momentary dissonance, by drawing attention to a neighboring structural tone, or by delaying, anticipating or thwarting an expected outcome.

The most widely held view of embellishment tones centers on their role in forming patterns of consonant and dissonant moments. Non-chordal embellishment tones follow a pattern of consonancedissonance-consonance (hereafter CDC pattern) - which in psychological terms may be deemed to create a brief experience of tension followed by release. It is thought that the degree of dissonance can be increased by having the dissonance in the CDC pattern fall on a metrically strong position. This occurs in the case of the suspension, the retardation, and the accented passing and accented neighbor tones. According to this view, another way of enhancing the degree of dissonance is by approaching the non-chordal tone by leap rather than by step - as in the case of the appoggiatura. Passing tones and neighbor tones are consequently regarded as comparatively tame in their ability to generate tension.

A variant of this account of embellishment tones is exemplified in the work of Leonard Meyer (1956). Meyer suggested that embellishment tones can be analyzed according to their interplay with the listener's expectations. Specifically, the flux of musical events can be characterized in terms of the generation of psychological expectations, and the subsequent fulfillment or thwarting of the expected consequence. Terms such as suspensions, retardations, and anticipations provide telling descriptive labels for the corresponding psychological experiences. Detailed psychological analyses of the expectation-related feelings evoked by the anticipation, the suspension, and the appoggiatura are given by Huron (2006, pp.245-247, 306-315).

An interesting alternative account of embellishment tones has been proposed by James Wright and Albert Bregman (1987). Wright and Bregman have suggested that the dissonances created by non-chordal tones are tempered perceptually when the tones forming the dissonance are strongly segregated into independent auditory streams. When two concurrent tones are captured by independent streams, their potential dissonance is suppressed or neutralized. Thus the degree to which a major seventh harmonic interval is perceived as dissonant is thought to depend on how well the constituent tones are integrated into their respective horizontal voices. When the segregation between possible streams is weak, any vertical dissonances are perceived as especially dissonant. Bregman (1990) has gone so far as to suggest:

"I think that if we were to hear, over headphones, a violin partita by Bach in one ear and a piano sonata by Beethoven in the other, and if these were well segregated perceptually, a combination consisting of one note from the Bach and one from the Beethoven would be neither consonant nor dissonant." (p.521)

Wright (1986) has proposed that the potential dissonance arising from non-chordal notes is minimized by independent part-writing. Wright has suggested that the observed increase in dissonance over the course of the history of Western music is reflected in the manner by which dissonant intervals are prepared. Over time, dissonances have been heightened by the dual practices of increasing the onset synchronization of the tones forming the dissonant interval and by decreasing the use of antecedent and consequent step motion. In short, much of the historical increase in musical dissonance is attributable to the weakening of auditory streaming. (For a review and commentary on this theory, see Huron, 1991a.)

The Wright/Bregman theory notwithstanding, a logically prior issue is to establish whether embellishment tones tend to enhance or detract from the perceptual segregation of the individual parts. If embellishment tones tend to enhance auditory streaming, what factors contribute to this? It is these questions that motivate the present study. 


\section{Embellishment Tones and Auditory Streaming}

Huron (2001) reviewed a number of principles that contribute to the perceptual independence of musical parts or voices. Four principles are most pertinent to a discussion of embellishment tones:

1. Pitch Proximity. The coherence of an auditory stream is maintained by close pitch proximity in successive tones within the stream. Pitch-based streaming is assured when pitch movement is within van Noorden's "fission boundary" (normally 2 semitones or less for tones less than about $700 \mathrm{~ms}$ in duration).

2. Tonal Fusion. Tonal fusion is the tendency for some concurrent sound combinations to cohere into a single sound image. Tonal fusion arises when the auditory system interprets certain frequency combinations as comprising partials of a single complex tone. The pitch interval that most encourages tonal fusion is the aptly named unison. The second most fused interval is the octave, whereas the third most fused interval is the perfect fifth (Stumpf, 1890; DeWitt \& Crowder, 1987). [2]

3. Pitch Co-modulation. Pitch co-modulation refers to the tendency for similar pitch motion to contribute to the perceptual fusion of concurrently-sounded tones. Co-modulated pitch motions might be precise with respect to $\log$ frequency (i.e., "parallel motion") or inexact with respect to log frequency (i.e., "similar motion"). Research has shown that both parallel and similar motions contribute to perceptual fusion, although the effect is much stronger for parallel motion, and is stronger for moving pitches than for static repetitions (Bregman \& Doehring, 1984; McAdams, 1982, 1984).

4. Onset Synchrony. Sounds are more apt to be perceived as components of a single auditory image when they are synchronized in time. That is, concurrent tones are more apt to be interpreted by the auditory system as constituents of a single complex sound event when the tones are temporally aligned. Since judgments about sounds tend to be made in the first few hundred milliseconds, the most important aspect of temporal coordination is the synchronization of sound onsets.

The experimental evidence in support of these four principles is extensive (see reviews in Bregman, 1990 and Huron, 2001). Moreover, there is similarly extensive evidence that these principles influence the organization of music (Carlsen, 1981; Dowling, 1967, 1973; Huron, 1987, 1989a, 1989b, 1991b, 1991c, 1993a, 1993b, 2001; Huron \& Fantini, 1989; Huron \& Mondor, 1994; Huron \& Sellmer, 1992; McAdams \& Bregman, 1979; van Noorden, 1975; Parncutt, 1989; Rasch, 1978, 1979, 1981, 1988 Vos, 1995).

The goal of this study is to determine whether the above principles play a significant role in the organization of embellishment tones. In brief, the method consisted of testing seven hypotheses that arise from the above four principles against a sample of music containing a large number and variety of embellishment tones.

\section{Musical Sample}

An appropriate sample might seek a broad selection of musical works from different periods and genres. However, for this study, the author elected to use a convenience sample of works that were originally assembled as part of an unrelated project.[3] The sample consisted of a selection of 50 of the 371 chorale harmonizations by Johann Sebastian Bach, edited by Riemenschneider (1941) but originally assembled by Erk (1850). The chorales are drawn from Bach's innumerable church cantatas; each chorale is based on a hymn melody common in Bach's day. Bach's chorale harmonizations have been widely regarded as one of the canonic repertories for Western harmonic practice. This repertory also provides a rich source of embellishment tones in a variety of harmonic contexts. The original sampling procedure had been purposely biased toward the selection of works in major keys. In total, 44 of the 50 selected harmonizations $(88 \%)$ were in major keys. By contrast, of the entire collection of 371 chorales, only 52 percent are in major keys. (A complete list of works analyzed is given in Appendix I.) This sampling process assumes that the modality of works has little effect on Bach's use of embellishment tones. 


\section{Identification of Embellishment Tones}

Each of the sampled works was analyzed by the author in order to identify all embellishment tones. The analysis proceeded according to traditional practice. Specifically, the analysis entailed: (1) identification of the key, (2) identification of the cadences - including changes of key area and modulations/tonicizations, (3) the assignment of (Roman numeral) tonal chord functions, and (4) the identification of the embellishment tones according to the taxonomy shown in Table 1.

In such analyses there is some latitude for interpretation, and so there exists the possibility of experimenter bias. Fortunately, the analyses were carried out before the current study was conceived. Nevertheless, there is room for disagreement concerning such analyses. For example, in many cases a purported embellishment tone may be better analyzed as establishing a new chord or harmonic function (see Figure 2). Several guiding principles are used by theorists to help establish which is the better of two or more competing analyses. In general, a sonority is more likely to be regarded as a distinct chord when:

1. the new sonority spells a coherent tertian chord

2. the moving part involves the bass voice

3. the resulting chord sequence shows a " $V$-of" or "vii-of" progression

4. the new chord onset conforms to the prevailing harmonic rhythm

5. more than one voice changes pitch.

In order to evaluate how well the author's analyses conform to common theoretical practice, two works were randomly selected (nos. $303 \& 328$ ) and given to two independent music theorists who produced their own analyses. [4] Of 110 sonorities in the two works, there was near unanimous agreement between the three theorists in the identification of chord functions. Of the 43 embellishment tones identified by all three theorists, there was agreement on the classification of all but one. Figure 2 shows this single discrepancy (from measure 6 of Chorale 328). The analysis hinges on how the chord on the third beat is identified. If the chord is identified as a $v i$ chord, then the $\mathrm{B}$ is a chordal tone and the $\mathrm{C \#}$ is a chromatic passing tone. Conversely, if the chord is identified as a $v i i^{\circ /} / V$ chord, then the $\mathrm{C} \#$ is a chordal tone and the $\mathrm{B}$ is an accented passing tone. Both the author and Theorist \#1 analyzed the passage in the former manner whereas Theorist \#2 analyzed the passage in the latter manner. In examining this passage, most theorists would agree that analyzing the passage as a $v i i^{0^{6}} / V$ is the superior analysis since chromatic pitches often signal changes of harmonic function and traditional practice prefers to regard progressions in terms of " $V$-of" or "vii-of" relations. Other theorists might argue that the sounding of the complete E minor triad in root position on the strong third beat would tend to dispose listeners to hear the $v i$ function in preference to the $v i i^{\circ} / V$ function.

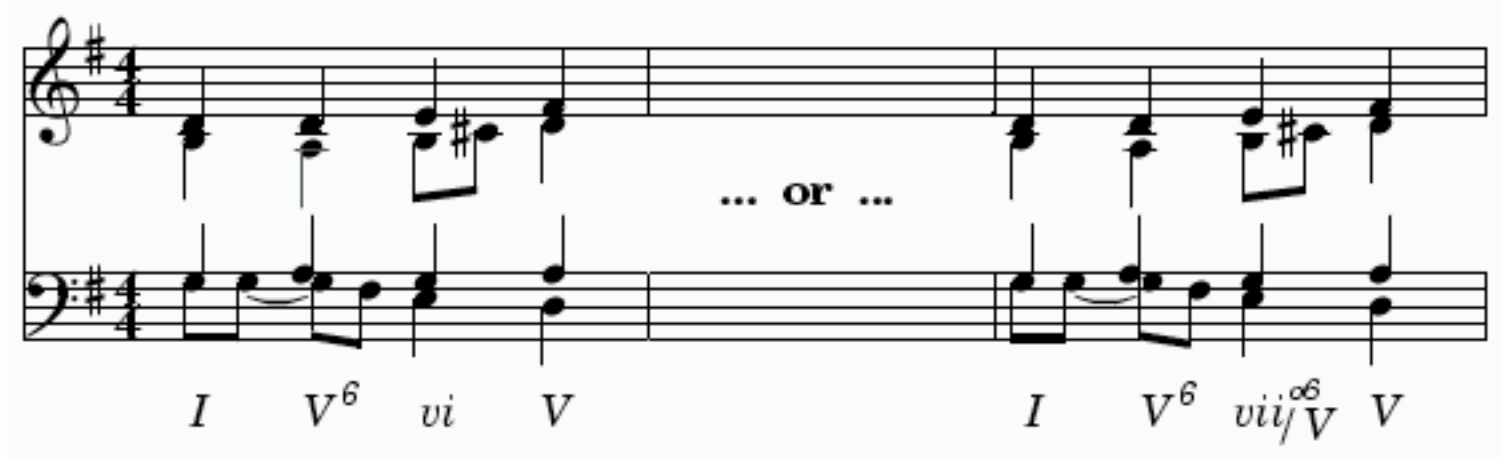

Fig. 2. An example of differing interpretations of embellishment tones (from measure 6 of chorale No. 328). The author and one other theorist identified the third chord as vi with the pitch $\mathrm{C \#} 4$ identified as an unaccented passing tone. A third theorist identified the chord as $v i i^{6 /} / V$ with the $\mathrm{C} \#$ deemed a chordal tone and the B deemed an accented passing tone. Most theorists would agree that the latter interpretation is superior. This point was the sole discrepancy between the three theorists. 
There may be no resolution for such analytic disputes. Indeed, a third view can be advanced that interprets the above passage as exhibiting both harmonic patterns, and that Bach was fond of creating progressions that display such multiple harmonic "meanings." Most theorists would recognize these differences as indicating slightly different analytic styles rather than indicating fundamental theoretical disagreements. Although there is some variability in the identification of embellishment tones, the general level of agreement between the analyses by the three theorists suggests that some confidence can be placed in such analyses. On the basis of this analysis, we might estimate the reliability of embellishment tone identification to be in the range of $42 / 43$ or better than 95 percent.

\section{Control Sample}

In order to test the effect of the presence of embellishment tones it is useful to be able to contrast our sample passages with comparable musical passages that do not contain any embellishments. One approach to assembling such a control sample would be to select works from a repertory known to contain many fewer embellishment tones. For example, one might assemble a sample of four-part hymns. Unfortunately, any observed differences between the test and control samples might simply reflect the different genres, periods, or composer preferences.

An alternative approach would be to modify the existing choral harmonizations by removing the embellishment tones. While making such modifications might seem presumptuous and perhaps suspect, in practice, the procedure for removing embellishments is not contentious among music theorists.

The embellishment tones were removed as follows: unaccented embellishments such as unaccented passing tones, neighbor tones, escape tones, repetitions, arpeggiations, etc. were deleted and the duration of the preceding chordal tone was extended proportionately. For accented embellishments such as accented passing tones, suspensions, retardations, appoggiaturas, etc., the embellishments were deleted and replaced by the ensuing resolved chordal tone. In the case of pedal tones, the sustained non-chordal portion was replaced by a rest.

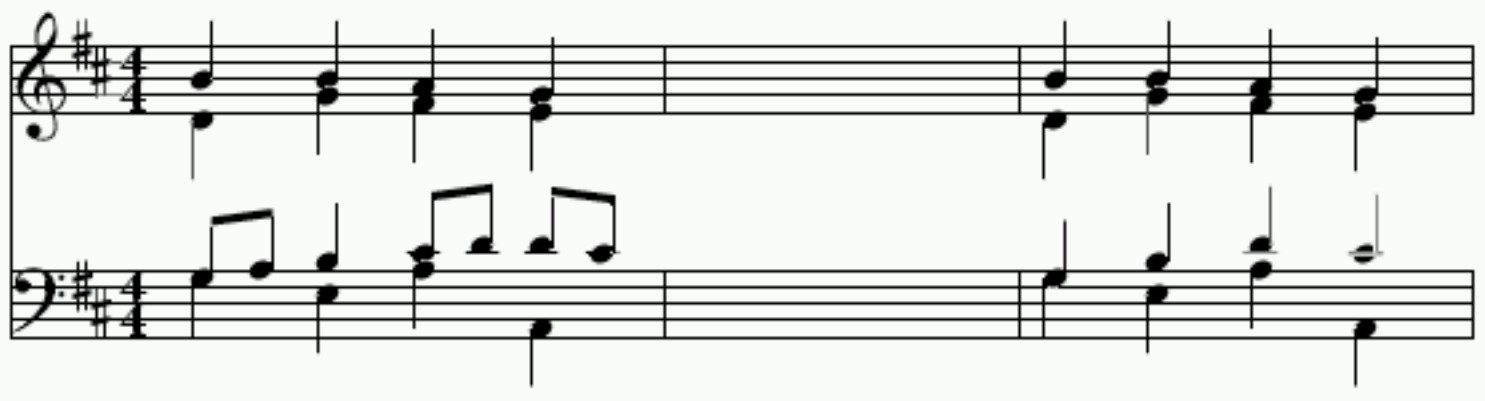

Fig. 3. A sample passage (measure 7 from chorale No. 255) illustrating the procedure used to create an unembellished control sample. Three embellishments have been eliminated from the tenor voice: the unaccented passing tone (A3), the accented passing tone (C\#4), and the suspension (D4). Associated chordal tones have been proportionally extended in duration. This process of elimination was applied to the entire sample corpus resulting in 50 unembellished renditions.

Figure 3 shows a sample passage (measure 7 from chorale No. 255) illustrating the embellished and unembellished versions. In this measure three embellishments have been eliminated from the tenor part. The unaccented passing tone (A3) has been deleted and the preceding $G$ extended to a quarter duration. The accented passing tone $(\mathrm{C \# 4})$ has been replaced by the ensuing D4 whose duration has been increased. Finally the suspension (D4) has been replaced by the resolving tone C\#4. This process of elimination was applied to the entire sample corpus resulting in 50 unembellished renditions containing 15 percent fewer notes than the original chorale harmonizations.

Having prepared both the actual and control samples, each work was encoded in a computer database. Specifically, the encoded data included a representation of each musical score, as well as harmonic information and labels marking the occurrence of various types of embellishment tones. The 
encoded data was then subjected to a stringent error detection regime (described in Huron, 1988). The ensuing analyses were carried out using the Humdrum Toolkit (Huron, 1995).

\section{ANALYSES}

\section{Pitch Proximity Analysis}

If the goal of pitch proximity influences the formation of embellishment tones then the following hypothesis should be supported:

H1. The presence of embellishment tones will reduce the average melodic interval size within voices.

In order to test this hypothesis, the average interval size in semitones was calculated for the soprano, alto, tenor, and bass voices for each of the 50 sample chorales. For example, the average size of melodic intervals in the soprano voice in chorale No. 9 is 1.55 semitones. What happens when the embellishments are removed?

Intervals were not calculated between notes separated by a rest, and tied notes were treated as a single tone. The average interval sizes were calculated for both the original and unembellished repertories. This resulted in 200 paired averages - the average interval size with and without embellishment tones for all four voices in the 50 chorales. Of the 200 paired measures $178(89 \%)$ proved to be larger when the embellishment tones were removed. (Three paired measures were exactly the same with embellishments present or absent.) Table 2 shows the aggregate average melodic interval sizes for all 50 samples chorales. Separate results are given for soprano, alto, tenor and bass voices.

Table 2

\section{Average Melodic Interval Size (in semitones)}

\begin{tabular}{l|cc}
\hline Voice & With Embellishments & Embellishments Excluded \\
\hline Soprano & 1.89 & 2.00 \\
Alto & 1.75 & 1.89 \\
Tenor & 2.02 & 2.26 \\
Bass & 3.25 & 3.64 \\
\hline All voices & 2.23 & 2.45 \\
\hline
\end{tabular}

On average, the presence of the embellishment tones reduces the average melodic interval size by 8.9 percent. The results suggest that Bach deploys embellishment tones in such a way as to improve the overall pitch proximity. This behavior is consistent with the goal of enhancing stream segregation.

Of course the only way to improve pitch proximity is to interpose the embellishment tone so that it lies between the preceding and following chordal tones. Some sense of the magnitude of the effect for the pitch proximity goal might be gained by determining the proportion of "interposed" embellishment tones-i.e., tones whose pitch lies between the preceding and ensuing chordal tones.

Table 3 provides a complete tally of the various types of embellishment tones found in the sample of choral harmonizations. We can answer the above question directly by determining the proportions of various types of embellishments. 
Table 3

Tally of Embellishment Tones by Type

\begin{tabular}{|c|c|c|c|c|}
\hline Embellishment & & Occurrence & & \\
\hline & Normal & Chromatic & Seventh* & Total \\
\hline Accented passing tones & 71 & 2 & 2 & 75 \\
\hline Unaccented passing tones & 788 & $31(40)+$ & $\begin{array}{c}409 \\
(418)+\end{array}$ & 1,237 \\
\hline Total: & & & & 1,312 \\
\hline Upper neighbor tones & 26 & 3 & 2 & 31 \\
\hline Lower neighbor tones & 126 & 19 & 2 & 147 \\
\hline Accented upper neighbors & 2 & 0 & 0 & 2 \\
\hline Accented lower neighbors & 6 & 1 & 0 & 7 \\
\hline Total: & & & & 187 \\
\hline Anticipations & 37 & & & 37 \\
\hline Suspensions & 295 & & & 295 \\
\hline Retardations & 9 & & & 9 \\
\hline Escape tones & 8 & & & 8 \\
\hline Appoggiaturas & $8(10)^{* *}$ & & & $8(10)^{* *}$ \\
\hline Changing tones & 12 & & & 12 \\
\hline Pedal tones & 7 & & & 7 \\
\hline Total: & & & & $376(378)^{* *}$ \\
\hline Total (all non-chordal embellishments): & & & & $1,875(1,877)^{* *}$ \\
\hline \multicolumn{5}{|l|}{ Chordal Embellishments: } \\
\hline Repetition tone & 12 & & & 12 \\
\hline Arpeggio tones & 265 & & 7 & 272 \\
\hline Total (all chordal embellishments): & & & & 284 \\
\hline \multicolumn{5}{|l|}{ Chordal Tones: } \\
\hline Chordal tones (unembellished) & 10,799 & & 8 & 10,807 \\
\hline $\begin{array}{r}\text { Total (chordal tones \& chordal } \\
\text { embellishmts): }\end{array}$ & & & & 11,091 \\
\hline
\end{tabular}

\footnotetext{
* Embellishment results in the addition of the seventh of the chord.

** Two appoggiaturas are identified in the analyses as questionable.

+ Nine unaccented passing tones are both chromatic and add the chordal seventh. The 9 embellishments are only counted once in the total.
}

By definition, passing tones $(n=1,312)$ represent interposed embellishments. Also by definition, neighbor tones (187) and changing tones (12) fail to interpose a pitch between the preceding and following chordal tones. In the case of appoggiaturas, escape tones and arpeggio chordal embellishments, each was examined to see whether the embellishment tone lay between the preceding and following tones. Of the 272 arpeggio embellishments 35 were found to have interposed pitches. All but 2 of the 10 appoggiaturas failed to involve interposed pitches. All 8 escape tones failed to produce interposed pitches.

Other types of embellishments do not readily fall into the category of either interposed or noninterposed tones. These include anticipations, suspensions, retardations, repeated tones, and pedal tones. If we exclude these from consideration, 1,349 of 1,801 eligible embellishment tones exhibited the "interposed pitch" pattern. That is, roughly 75 percent of embellishment tones are directly consistent with the goal of enhancing pitch proximity within a voice or part.

\section{Tonal Fusion Analysis}

Recall that tonal fusion occurs most frequently in the case of unison and octave intervals. This suggests that a simple approach to investigating tonal fusion might be to examine the relationship between embellishment tones and the duplication of pitches or pitch classes. Two hypotheses might be identified: 
H2. The presence of embellishment tones will tend to reduce the total duration of duplicated pitches (unisons).

H3. The presence of embellishment tones will tend to reduce the total duration of duplicated pitch classes (unisons, octaves, fifteenths, etc.).

In order to test hypothesis 2 , we can calculate the total duration of unison pitch duplication when the embellishments are present in the sample, and compare this to the total duration of unison pitch duplication when the embellishments are removed.

Pitch duplication was measured for each voice separately. In the case of the soprano voice, for example, at each moment in the scores, it was determined whether any other voice was sounding the same pitch at the same time, and if so, for how long. A running tally was maintained of the total aggregate duration of unison doubling for the given voice. Table 4 compares the results for both the embellished and unembellished version of the chorales. (Duration values reported are in quarter-note units.) Also shown is the percentage of reduction in unison doubling from the unembellished version. As can be seen, the presence of the embellishments reduces the aggregate unison pitch doubling in all four voices.

Table 4

Total Duration of Unison Pitch Doubling (in quarter durations)

\begin{tabular}{l|ccc}
\hline & Embellished & Unembellished & \% Reduction \\
\hline Soprano & 143.5 & 148.0 & 3.0 \\
Alto & 174.0 & 188.0 & 7.4 \\
Tenor & 208.0 & 248.5 & 16.3 \\
Bass & 182.5 & 216.5 & 15.7 \\
\hline All voices & 708.0 & 801.0 & 11.6 \\
\hline
\end{tabular}

Hypothesis 3 raises a more general prediction, namely that the presence of embellishment tones will tend to reduce the total duration of duplicated pitch classes (including octaves, fifteenths, etc.). Once again, we can test this hypothesis by calculating the total duration of pitch-class duplication for both the embellished and unembellished versions of the chorale sample. Since we have already shown a tendency to avoid exact pitch duplication, a more stringent test of hypothesis 3 would exclude unisons from consideration. Table 5 shows the pertinent results-identifying the aggregate duration of pitch-class duplication where exact pitch duplication (unisons) have been omitted. Once again, the aggregate duration is smaller in the embellished versions for all four voices. These results are consistent with the goal of reducing the probability of tonal fusion.

Table 5

Total Duration of Pitch-class Doubling (Unisons Excluded)

\begin{tabular}{l|ccc}
\hline & Embellished & Unembellished & \% Reduction \\
\hline Soprano & 1047.0 & 1159.75 & 9.7 \\
Alto & 671.75 & 817.5 & 17.8 \\
Tenor & 850.25 & 1005.25 & 15.4 \\
Bass & 1540.0 & 1785.0 & 13.7 \\
\hline All voices & 4109.0 & 4767.5 & 13.8 \\
\hline
\end{tabular}

If Bach is truly endeavoring to reduce pitch-class duplication, then we ought to be able to predict which voice or part will be embellished, simply on the basis of which parts share duplicated pitch-classes. For example, consider all sonorities consisting of 3 unique chromas (as would be found in a triad with the duplication of one pitch-class). If embellishment tones serve to reduce tonal fusion, then we might predict that the most likely voices to "receive" an embellishment would be a voice that duplicates an already sounding pitch-class. Expressed as a hypothesis: 
H4. The voice or part most likely to be embellished will be one that duplicates a pitch-class.

The consequences of hypothesis 4 are illustrated in Figure 4. In both passages shown in Figure 4, the pitch-class ' $\mathrm{C}$ ' is doubled between the bass and alto voices. Hypothesis 4 would predict that any ensuing embellishment would be more likely to occur in either the bass or alto voices rather than in the soprano or tenor. Hence, hypothesis 4 would predict that the example on the right would be more probable than the example on the left.

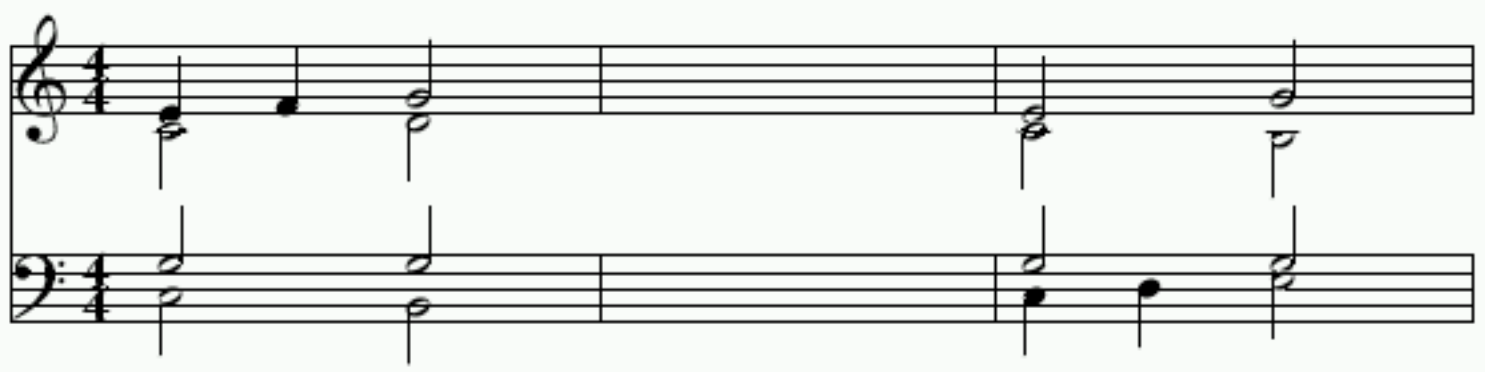

Fig. 4. Schematic illustration of hypothesis 4, i.e., that embellishments are more likely to occur in voices that are engaged in pitch-class duplication. In both the left and right examples, the pitch-class ' $\mathrm{C}$ ' is doubled between the bass and alto voices. Hypothesis 4 predicts that any ensuing embellishment would be more likely to occur in either the bass or alto voices rather than in the soprano or tenor voices. Hence, hypothesis 4 would predict that the passage on the right would be more probable than the passage on the left.

In order to test Hypothesis 4, all chords were identified in which three pitch-classes were present and two parts duplicated a single pitch-class. The voices duplicating the pitch-class where then noted. If the next moment in the score exhibited a single embellishment tone, then one of the two noted voices was randomly selected and used to predict the voice in which the ensuing embellishment appears. The probability of selecting the correct voice containing the embellishment is 1 in 4 . Table 6 displays the results:

Table 6

Prediction of Embellished Voice Based on Antecedent PC Doubling

\begin{tabular}{l|cccc}
\hline & Correct & Incorrect & $\boldsymbol{p}$ () & null $\boldsymbol{p}$ () \\
\hline Soprano & 24 & 47 & 0.34 & 0.25 \\
Alto & 38 & 125 & 0.23 & 0.25 \\
Tenor & 65 & 133 & 0.33 & 0.25 \\
Bass & 118 & 167 & 0.41 & 0.25 \\
\hline Total & 245 & 472 & 0.34 & 0.25 \\
\hline
\end{tabular}

Of 717 eligible passages, the voice containing the embellishment was correctly predicted in 245 cases for a 34 percent success rate compared to 25 percent for chance guessing. Significant results are evident in all voices except the alto - where performance was no different from chance. In general, there is indeed a tendency to introduce an embellishment in one of the parts whose pitch-class is duplicated in another voice. Once again, this result is consistent with efforts to avoid or minimize tonal fusion, which in turn is consistent with the goal of enhancing the perceptual independence of the individual parts.

\section{Pitch Co-modulation Analysis}

If the avoidance of pitch co-modulation influences the deployment of embellishment tones then the following hypothesis follows: 
H5. In the absence of embellishment tones, the average pitch movement correlations between parts will increase.

In order to test this hypothesis, Pearson's coefficient of correlation was calculated between all pairs of voices for each of the 50 sampled works. A positive correlation indicates that pitch contours tend to rise and fall together; a negative correlation indicates that pitch contours tend to favor contrary motion. A correlation near zero can arise whenever (1) no relationship exists between the contours of the two voices, (2) roughly equivalent amounts of similar and contrary motions occur, (3) pitch contours are dominated by oblique motions, or (4) some combination of the above.

Correlation values were calculated for each of the six possible voice pairings (S-A, S-T, S-B, A-T, A-B, T-B). After discarding the embellishment tones, the pitch-contour correlations were re-calculated. Of the 300 correlations for the 50 chorales, 166 proved to be bigger (or more positive) when the embellishment tones were removed; 131 were smaller, and three were equivalent. Although not a big effect, this difference proves to be statistically significant (Yates' chi $=3.9 ; \mathrm{df}=1 ; \mathrm{p}=0.0485$ ). On average, this means that Bach deploys embellishment tones in such a way as to reduce co-modulated pitch movements. This behavior is consistent with the goal of enhancing stream segregation.

\section{Onset Synchrony}

As noted earlier, sounds are more apt to cohere and be perceived as components of a single auditory image when they are synchronized in time. One way to increase the perceptual independence of the parts is to decrease the number of moments when several voices have concurrent onsets. Given the nature of embellishment tones, there is little need to test any hypotheses regarding this question. Most embellishments, such as unaccented passing tones, necessarily create an asynchronous onset. Moreover, even embellishments that coincide with chord onsets (such as suspensions or accented passing tones) tend to engender an ensuing chordal tone that appears in isolation. The original sample of chorale harmonizations contains some 5,362 vertical sonorities or simultaneities. By contrast, the unembellished equivalents contain just 3,715 vertical sonorities. That is, the addition of embellishment tones increases the number of onset moments by 44 percent.

Of the 2,161 chordal and non-chordal embellishments in the original chorales, 58 percent appear in isolation or cause an ensuing isolated tone. A further 872 embellishments appear as concurrent pairs, such as tandem passing tones. In total, 98 percent of embellishments appear as either isolated tones, or in tandem with one other tone, or provoke an ensuing isolated tone. By contrast, the vast majority of chordal tones appear as part of a four-note block chord onset. In other words, Bach adds embellishment tones in a way that significantly increases the number of asynchronous tone onsets. While other interpretations are possible, this result is consistent with the goal of increasing the perceptual independence of the concurrent parts.

\section{EMBELLISHMENT TURN-TAKING}

In a study of the perception of concurrent melodies, Sloboda and Edworthy (1981) suggested that listeners are able to attend to only a single sound at a time. They suggested that mental images of multiple concurrent lines of sound might arise from rapid shifts of attention between the lines. This hypothetical attentional process might be likened to a form of perceptual "one-handed juggling" in which several images formed from the auditory scene (the balls) are refreshed in alternating succession by a single attentional mechanism (the hand).

If Sloboda and Edworthy's conjecture is correct, it would have repercussions for the optimum pattern of note onsets in multi-part music. Each isolated tone onset might be expected to draw the listener's attention and so rekindle the mental image of the auditory stream to which that note belongs. At the same time, one might expect the salience of a given stream to decline over time, especially if attention has not been recently drawn to that stream.

In short, the notion of a single-channel model of auditory attention would imply that some sort of sequential "refreshing" of the individual streams would be needed if the musical goal is to evoke multiple concurrent lines of sound. Since, by definition, asynchronous onsets must be sequential rather than 
concurrent, we would expect each concurrent stream to be successively 'highlighted' using asynchronous onsets. Bach would "take turns" highlighting the presence of each musical voice or part through the use of asynchronous notes.

Two hypothesis arise from this conjecture:

H6. The proportion of asynchronous onsets should be similar in each of the concurrent voices.

That is, we would predict roughly equivalent numbers of isolated sounding tones in each of the soprano, alto, tenor, and bass voices.

H7. That for all moments in a work, the most probable next asynchronous onset will occur in that musical part or voice which has gone the longest without an asynchronous onset.

In short, the stream most likely to be refreshed would be the stream with the least perceptual salience. Using our juggling metaphor, we would say that the next ball most likely to be tossed into the air is that ball nearest to the ground.

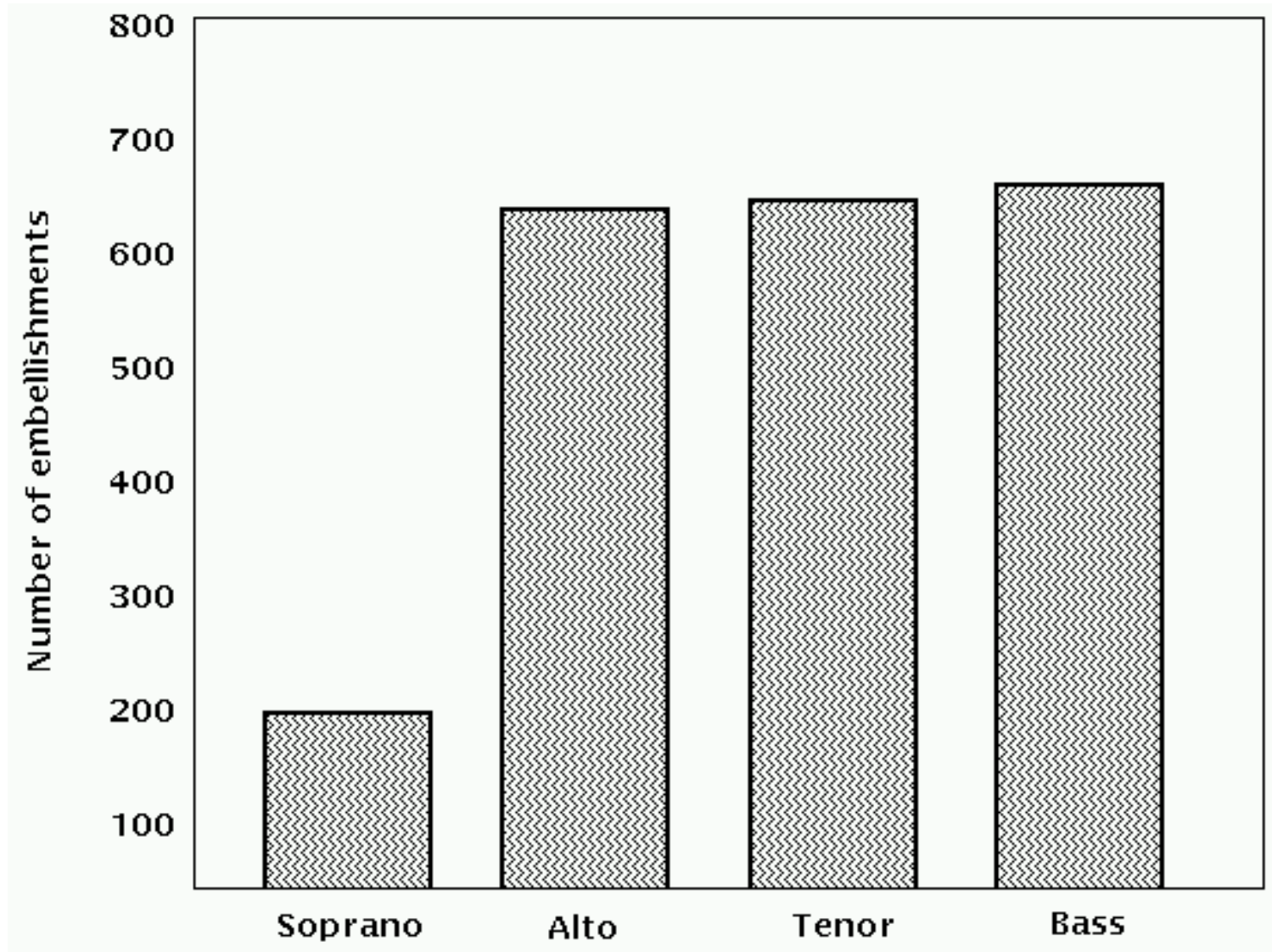

Fig. 5. Number of chordal and non-chordal embellishments according to voice. Roughly equivalent numbers are evident in the alto, tenor, and bass voices. The reduced number of embellishments in the soprano voice may reflect Bach's reluctance to modify the original hymn melodies (see text).

In order to test hypothesis 6 , we can simply count the number of single-sounding tones in each of the four voices. Figure 5 shows the pertinent counts. As can be seen, the counts for the alto, tenor and bass voices are comparable, however, there is a notable lack of isolated tones occurring in the soprano voice.

Prima facie this result is not consistent with hypothesis 6 . However, a plausible post hoc reason for this discrepancy can be offered. Since the chorale harmonizations typically involved the harmonization of existing melodies, the soprano line is consequently more constrained than the other voices. In arranging 
these chorales, it is likely that Bach could take fewer liberties with the melody. Since there are no significant differences between the lower three parts in terms of the total number of notes or the total number of asynchronous notes, the evidence against hypothesis 6 is equivocal.

Hypothesis 7 predicts the relative order of occurrence of embellishments from voice to voice. Specifically, hypothesis 7 predicts that the most probable next asynchronous onset will occur in that music part which has gone longest without an asynchronous onset.

The prediction was tested as follows. A running tab was kept of the voice having the least recent (most distant) asynchronous onset. Whenever a new asynchronous onset was encountered, the voice in which the onset occurred was compared with the voice of the least recent asynchronous onset. If two or more voices had equally distant asynchronous onsets, then a random selection was made between the voices. Table 7 shows the number of hits and misses for each of the four voices. The total or aggregate predictability for all four voices is 32 percent correct whereas a chance level would be 25 percent. In the first instance this result is consistent with hypothesis 7 . However, significant differences are evident between the voices. The bass voice was most poorly predicted, operating at the chance level. The soprano voice proved to be the most accurately predicted at 49 percent, where chance would be 25 percent.

The failure to predict asynchronous onsets in the bass is difficult to interpret. It may be that the relative harmonic importance of the bass places greater restrictions on its movement so the composer's options for introducing embellishments is more constrained.

\section{Table 7}

Prediction of Embellished Voice Based on Antecedent PC Doubling

\begin{tabular}{l|cccc}
\hline & Correct & Incorrect & $\boldsymbol{p}()$ & null $\boldsymbol{p}()$ \\
\hline Soprano & 48 & 50 & 0.49 & 0.25 \\
Alto & 137 & 217 & 0.39 & 0.25 \\
Tenor & 109 & 255 & 0.30 & 0.25 \\
Bass & 91 & 290 & 0.24 & 0.25 \\
\hline Total & 382 & 812 & 0.32 & 0.25 \\
\hline
\end{tabular}

Since the soprano voice contains the least number of total asynchronous onsets, the results suggest that Bach was especially likely to add an embellishment to the soprano part when the voice had gone without an asynchronous onset for some time. Using our juggling analogy, the juggler is even more likely to grab a ball which has had plenty of time to fall towards the floor. In short, in light of the fewer number of asynchronous onsets in the soprano voice, the fact that embellishments may be better predicted for this voice lends further support to the concept of "stream refresh."

\section{CONCLUSION}

In contrasting embellished and unembellished versions of 50 choral harmonizations, we were able to test a number of hypotheses pertaining to the perceptual independent of the concurrent parts. In general, the presence of embellishment tones reduces the average melodic interval size within voices. In fact, threequarters of all embellishment tones exhibit pitches that are interposed between the pitches of the antecedent and consequent chordal tones. These observations are consistent with the goal of close within-voice pitch proximity which is known to enhance the perceptual independence of voices or streams.

In the case of tonal fusion, we found that the presence of embellishment tones in Bach tends to reduce the duration of duplicated pitches (harmonic unisons). Also, the presence of embellishment tones tends to reduce the duration of duplicated pitch classes apart from unisons (i.e., octaves, fifteenths, etc.). Both of these results are consistent with the goal of reducing the likelihood of inadvertent tonal fusion between the parts. Moreover, we found that the voice or part most likely to be embellished is one that duplicates a pitch-class.

With regard to pitch co-modulation, we found that, in the absence of embellishment tones, the average pitch movement correlations between parts increases. That is, embellishment tones either reduce the use of similar and parallel motions, or increase the use of oblique and contrary motions, or both. 
Onset asynchrony is known to facilitate perceptual segregation of concurrent auditory streams. Almost by definition, embellishment tones provide many opportunities to introduce a degree of asynchrony between the concurrent voices. However, it is not simply the case that the proportion of asynchronous onsets is increased by the presence of embellishment tones. We have seen that Bach's compositional practice is consistent with a juggling strategy in which "turn-taking" is commonplace. With the exception of the bass, there is a tendency for the next asynchronous onset to occur in that voice or part which has gone longest without an asynchronous onset. Although other accounts might be offered to explain this practice, we have noted in this study that Bach's practice is consistent with a stream segregation goal in which asynchronous onset cues are used to refresh the presumed auditory images for each voice.

Viewed in the aggregate, the results of this study are consistent with the view that embellishment tones in Bach's chorale harmonizations tend to aid in the perceptual segregation of the concurrent voices. It is important to recognize that this pattern of organization does not contradict the various theories of embellishment tones outlined earlier. The principal function of embellishment tones may well prove to be one of "adding interest," for example, by adding dissonance, by drawing attention to neighboring structural tones, or by delaying or heightening a sense of expectation. However, the foregoing analyses suggest that the manner by which such interest is garnered must be consistent with the goal of maintaining the perceptual independence of the musical parts.

\section{NOTES}

[1] School of Music, 1866 College Road, Ohio State University, Columbus, Ohio, 43210, USA.

[2] Following Stumpf, many music researchers have assumed that tonal fusion and tonal consonance are the same phenomenon, and that both arise from simple integer frequency ratios. However, modern psychoacoustic research does not support Stumpf's original view. See Bregman (1990) and Huron (2001) for pertinent reviews.

[3] The goal of this earlier project was to create a test suite for evaluating computer programs that perform automatic harmonic analysis.

[4] The author wishes to thank theorists Leonard Enns and Terrence Kroetsch for carrying out the independent analyses.

\section{REFERENCES}

Aldwell, E., \& Schachter, C. (1979). Harmony and Voice Leading. Vol. 2. New York: Harcourt Brace Jovanovich.

Bregman, A. S. (1990). Auditory Scene Analysis; The Perceptual Organization of Sound. Cambridge, MA: M.I.T. Press.

Bregman, A. S., \& Doehring, P. (1984). Fusion of simultaneous tonal glides: The role of parallelness and simple frequency relations. Perception \& Psychophysics, Vol. 36, No. 3, pp. 251-256.

Carlsen, J.C. (1981). Some factors which influence melodic expectancy. Psychomusicology, Vol. 1, pp. 1229.

DeWitt, L. A., \& Crowder, R. G. (1987). Tonal fusion of consonant musical intervals: The oomph in Stumpf. Perception \& Psychophysics, Vol. 41, No. 1, pp. 73-84. 
Dowling, W. J. (1967). Rhythmic Fission and the Perceptual Organization of Tone Sequences. Ph.D. dissertation, Harvard University, Cambridge, MA.

Dowling, W. J. (1973). The perception of interleaved melodies. Cognitive Psychology, Vol. 5, pp. 322-337.

Erk, L.C. (Ed.) (1850). Johann Sebastian Bach's mehrstimmige Choralgesänge und geistliche Arien ... Leipzig: C.F. Peters.

Hindemith, P. (1944). Traditional Harmony. Book 1, 2nd ed. London: Schott \& Co.

Horwood, F. J. (1948). The Basis of Harmony. Toronto: Gordon V. Thompson.

Huron, D. (1987). Auditory stream segregation and voice independence in multi-voice musical textures. Paper presented at the Second Conference on Science and Music, City University, London, U.K.

Huron, D. (1988). Error categories, detection and reduction in a musical database. Computers and the Humanities, Vol. 22, No. 4, pp. 253-264.

Huron, D. (1989a). Voice Segregation in Selected Polyphonic Keyboard Works by Johann Sebastian Bach. Ph.D. dissertation, University of Nottingham, Nottingham, England.

Huron, D. (1989b). Voice denumerability in polyphonic music of homogeneous timbres. Music Perception, Vol. 6, No. 4, pp. 361-382.

Huron, D. (1991a). Albert S. Bregman: Auditory Scene Analysis: The Perceptual Organization of Sound [review of]. Psychology of Music, Vol. 19, No. 1, pp. 77-82.

Huron, D. (1991b). The avoidance of part-crossing in polyphonic music; perceptual evidence and musical practice. Music Perception, Vol. 9, No. 1, pp. 93-104.

Huron, D. (1991c). Tonal consonance versus tonal fusion in polyphonic sonorities. Music Perception, Vol. 9 , No. 2, pp. 135-154.

Huron, D. (1993a). Note-onset asynchrony in J.S. Bach's two-part Inventions. Music Perception, Vol 10, No. 4, pp. 435-443.

Huron, D. (1993b). A derivation of the rules of voice-leading from perceptual principles. Journal of the Acoustical Society of America, Vol. 93, No. 4, p. S2362.

Huron, D. (1995). The Humdrum Toolkit: Reference Manual. Stanford, California: Center for Computer Assisted Research in the Humanities.

Huron, D. (2001). Tone and voice: A derivation of the rules of voice-leading from perceptual principles. Music Perception, Vol. 19, No.1, pp. 1-64.

Huron, D. (2006). Sweet Anticipation: Music and the Psychology of Expectation. Cambridge, MA: MIT Press.

Huron, D., \& Fantini, D. (1989). The avoidance of inner-voice entries: Perceptual evidence and musical practice. Music Perception, Vol. 7, No. 1, pp. 43-47.

Huron, D., \& Mondor, T. (1994). Melodic line, melodic motion, and Fitts' law. Unpublished MS.

Huron, D., \& Sellmer, P. (1992). Critical bands and the spelling of vertical sonorities. Music Perception, Vol. 10, No. 2, pp. 129-149. 
McAdams, S. (1982). Spectral fusion and the creation of auditory images. In M. Clynes (Ed.), Music, Mind, and Brain; The Neuropsychology of Music. New York \& London: Plenum Press, pp. 279-298.

McAdams, S. (1984). Spectral Fusion, Spectral Parsing and the Formation of Auditory Images. Ph.D. dissertation, Stanford University, Palo Alto, CA.

McAdams, S., \& Bregman, A. S. (1979). Hearing musical streams. Computer Music Journal, Vol. 3, No. 4, pp. 26-43,60,63.

Meyer, L.B. (1956). Emotion and Meaning in Music. Chicago: University of Chicago Press.

van Noorden, L.P.A.S. (1975). Temporal Coherence in the Perception of Tone Sequences. Doctoral dissertation, Technisch Hogeschool Eindhoven; published Eindhoven: Druk vam Voorschoten.

Parncutt, R. (1989). Harmony: A Psychoacoustical Approach. Berlin: Springer Verlag.

Piston, W. (1962). Harmony. New York: W.W. Norton.

Rasch, R. A. (1978). The perception of simultaneous notes such as in polyphonic music. Acustica, Vol. 40, pp. 21-33.

Rasch, R. A. (1979). Synchronization in performed ensemble music. Acustica, Vol. 43, pp. 121-131.

Rasch, R. A. (1981). Aspects of the Perception and Performance of Polyphonic Music. Doctoral dissertation. Utrecht, The Netherlands: Elinkwijk BV.

Rasch, R. A. (1988). Timing and synchronization in ensemble performance. In J. Sloboda (Ed.), Generative Processes in Music; The Psychology of Performance, Improvisation, and Composition. Oxford: Clarendon Press, pp. 70-90.

Riemenschneider, A. (1941). 371 Harmonized Chorales and 69 Chorale Melodies with Figured Bass by Johann Sebastian Bach. New York: G. Schirmer.

Sloboda, J., \& Edworthy, J. (1981). Attending to two melodies at once: the effect of key relatedness. Psychology of Music, Vol. 9, No. 1, pp. 39-43.

Stumpf, C. (1890). Tonpsychologie. Vol. 2. Leipzig: S. Hirzel.

Vos, J. (1995). Perceptual separation of simultaneous complex tones: The effect of slightly asynchronous onsets. Acta Acustica, Vol. 3, pp. 405-416.

Wright, J. K. (1986). Auditory Object Perception: Counterpoint in a New Context. Masters thesis, McGill University, Montréal, PQ.

Wright, J. K. \& Bregman, A. S. (1987). Auditory stream segregation and the control of dissonance in polyphonic music. Contemporary Music Review, Vol. 2, pp. 63-93. 


\section{APPENDIX I}

No. 009 Ermuntre dich, mein schwacher Geist No. 019 Ich hab' mein' Sach' Gott heimgestellt No. 024 Valet will ich dir geben No. 028 Nun komm, der Heiden Heiland No. 030 Jesus Christus, unser Heiland No. 032 Nun danket alle Gott No. 046 Vom Himmel hoch, da komm' ich her No. 048 Ach wie nichtig, ach wie flüchtig No. 054 Lobt Gott, ihr Christen, allzugleich No. 068 Wenn wir in hoechsten Nöten sein No. 069 Komm, heiliger Geist, Herre Gott No. 088 Helft mir Gott's Güte preisen No. 098 O Haupt voll Blut und Wunden No. 101 Herr Christ, der ein'ge Gott's-Sohn No. 110 Vater unser im Himmelreich No. 117 Nun ruhen alle Wälder

No. 124 Auf, auf, mein Herz, und du mein ganzer Sinn

No. 136 Herr Jesu Christ, dich zu uns wend'

No. 153 Alle Menschen müssen sterben No. 157 Wo Gott zum Haus nicht gibt No. 158 Der Tag, der ist so freudenreich No. 165 O Lamm Gottes, unschuldig No. 176 Erstanden ist der heil'ge Christ No. 177 Ach bleib bei uns, Herr Jesu Chris

No. 183 Nun freut euch, lieben Christen, g'mein

No. 187 Komm, Gott Schoepfer, heiliger Geist

No. 200 Christus ist erstanden, hat überwunden No. 201 O mensche, bewein' dein' Sünde gross No. 217 Ach Gott, wie manches Herzeleid No. 223 Ich dank' dir, Gott, für all' Wohltat No. 224 Das walt' Gott Vater und Gott Sohn No. 248 Se Lob und Ehr' dem höchsten Gut No. 255 Was frag' ich nach der Welt No. 258 Meine Augen schliess' ich jetzt No. 268 Nun lob', mein' Seel', den Herren No. 272 Ich dank' dir, lieber Herre No. 273 Ein' feste Burg ist unser Gott No. 276 Lobt Gott, ihr Christen, allzugleich No. 282 Freu' dich sehr, O meine Seele No. 290 Es ist das Heil uns kommen her No. 299 Meinen Jesum lass ich nicht No. 303 Herr Christ, der ein'ge Gott's sohn No. 306 O Mensch, bewein' dein' Sünde gross No. 323 Wie schön leuchtet der Morgenstern No. 328 Liebster Jesu, wir sind hier No. 350 Jesu, meiner Seelen Wonne No. 354 Sei Lob und Ehr' dem höchsten Gut No. 361 Du Lebensfürst, Herr Jesu Christ No. 366 O Welt, sieh hier dein Leben No. 368 Hilf, Herr Jesu, lass gelingen 